SINERGI 2019, Volume 16 (2): 205-214

DOI : http://dx.doi.org/10.31963/sinergi.v16i2.1516

\title{
Audit Energi di PT. Satwa Utama Raya 8
}

\author{
Remigius Tandioga ${ }^{1^{*}}$, Suryanto ${ }^{2}$, Iswahyudin $\operatorname{Hasan}^{3}$ dan Ali Kamal Umar ${ }^{4}$ \\ 1,2,3,4 Jurusan Teknik Mesin, Politeknik Negeri Ujung Pandang, Makassar 90245, Indonesia \\ "remigius@poliupg.ac.id
}

\begin{abstract}
Energy audit is one of the activities to find the value of energy consumption that is used daily and measure how much energy is used and how much is not useful. This research was conducted to obtain the value of energy consumption intensity and to look for opportunities for energy savings and cost savings based on actual conditions in the field at PT Satwa Utama Raya 8, activities undertaken include initial energy audits and detailed energy audits. From the results of this study, the average value of the intensity of energy consumption in 2014 was $3,219 \mathrm{~kJ} / \mathrm{kg}$ and in 2015 it was $5,277 \mathrm{~kJ} / \mathrm{kg}$. The great potential for energy savings at PT Satwa Utama Raya 8 is $16.34 \%$ or equivalent to Rp. $60,458,000$.
\end{abstract}

Keywords: Energy Audit; Initial Energy Audit; Detailed Energy Audit; Energy Consumption Intensity

\begin{abstract}
Abstrak: Audit energi adalah salah satu kegiatan mencari nilai dari konsumsi energi yang dipakai sehari-hari dan mengukur berapa besar energi yang digunakan serta berapa pula tidak berguna. Penelitian ini dilakukan untuk mendapatkan nilai intensitas konsumsi energi (IKE) serta mencari peluang-peluang untuk penghematan energi dan penghematan biaya berdasarkan kondisi aktual di lapangan pada PT Satwa Utama Raya 8, kegiatan yang di lakukan meliputi audit energi awal dan audit energi rinci. Dari hasil penelitian ini didapatkan nilai rata-rata dari intesitas konsumsi energi pada tahun 2014 adalah $3.219 \mathrm{~kJ} / \mathrm{kg}$ dan pada tahun 2015 adalah $5.277 \mathrm{~kJ} / \mathrm{kg}$. Besar potensi penghematan energi pada PT Satwa Utama Raya 8 diperoleh 16,34 \% atau setara dengan Rp.60.458.000.
\end{abstract}

Kata kunci : Audit Energi; Audit Energi Awal; Audit Energi Rinci; Intensitas Konsumsi Energi

\section{PENDAHULUAN}

Industri merupakan suatu usaha yang operasionalnya yang umumnya membutuhkan energi besar. Energi untuk operasional dapat menjadi faktor penentu untuk mencapai target produksi. Untuk menekan biaya produksi, pihak owners industri akan berusaha menekan penggunaan energi listrik menjadi seminimal mungkin. Manjemen energi perlu diterapkan untuk menghemat energi, baik dari sumber energi terbarukan maupun sumber energi tak terbarukan. Penerapan manjemen energi meliputi perencanaan, pengoperasian, pengawasan dan audit pemanfaatan energi serta koreksi penggunaan energi yang tepat guna. Pada sebuah industri, efektifitas dan efisiensi pemakaian energi sangat penting untuk mendapatkan profit yang lebih besar.

PT Satwa Utama Raya yang merupakan industri yang bergerak pada bidang peternakan, khusunya memproduksi telur ayam. Dalam opersionalnya banyak membutuhkan energi baik energi listrik maupun energi bahan bakar solar. Biaya produksi dari komponen energi berkisar $24 \%$. Terdapat potensi penghematan energi pada penggunaan energi yang diperoleh dari proses audit energi yang telah dilakukan. Untuk merealisasikan potensi penghematan penggunaan energi selanjutnya dipaparkan dalam bentuk rekomendasi.

Audit energi adalah salah satu kegiatan pengambilan data yang tentunya dari hasil pengukuran, untuk mengetahui dan diletakkan dimana, bagaimana, berapa dan jenis energi apa yang dipergunakan oleh industri dari keseluruhan sistem yang melengkapi bangunan industri tersebut menurut fungsi dan kegunaan dari bangunan industri tersebut (Direktorat Jenderal Listrik dan Pengembangan Energi Departemen Pertambangan dan Energi 1996). Audit energi juga dapat dikatakan sebagai salah satu 
langkah awal untuk melaksanakan suatu program konversi energi yang mana hasil energi merupakan rekomendasi untuk pelaksanaan konservasi energi.

Audit energi awal (Preliminary Energy Audit = PEA), pada dasarnya merupakan pengumpulan data awal dan ada beberapa istilah yang dipakai, misalnya audit singkat (short audity) atau survey awal (initial survey).

Dalam hal ini,

Intesitas konsumsi energi $(\mathrm{IKE})=\sum$ energi $/ \mathrm{kg}$ telur

$\sum$ energi $=$ Energi listrik + energi bahan bakar

Energi Listrik $=$ LWBP kWh + WBP kWh

Keterangan :

LWBP = Luar waktu beban puncak

WBP $\quad=$ Waktu beban puncak

Untuk perhitungan energi bahan bakar dapat dikalikan dengan nilai kalor bahan bakar sehingga dapat dilihat pada rumus di bawah ini.

Energi BBM = Nilai kalor BBM x Pemakaian solar

Keterangan :

Energi $\mathrm{BBM}=$ Energi Bahan Bakar Solar

Nilai Kalor BBM = Nilai Kalor Bahan Bakar Solar

Pada perhitungan tersebut, nilai dari intensitas energi dan nilai dari energi bahan bakar sudah didapatkan, sehingga nilai dari IKE dapat dihitung.

$$
\mathrm{IKE}=\frac{\text { Energi Listrik+Energi BBM }}{\text { jumlah produksi (kg) }}(\mathrm{kJ} / \mathrm{kg})
$$

Pada umumnya audit energi awal tidak cukup mengidentifikasi keseluruhan konsumsi energi. Oleh karena itu, audit energi rinci diperlukan pada tahap selanjutnya. Audit energi rinci (Detailed Energy Audit = DEA), merupakan survei dengan memakai instrumen untuk menyelidiki peralatan-peralatan pemakai energi, yang selanjutnya diteruskan dengan analisis secara rinci terhadap masing-masing komponen, peralatan, grup-grup komponen yang melengkapi bangunan, guna mengidentifikasi jumlah energi yang dikonsumsi oleh peralatan [1]. Komponen bagian-bagian tertentu dari bangunan atau keseluruhuan bangunan sehingga pada akhirnya dapat disusun aliran energi keseluruhan bangunan.

Jati Untoro dkk [2], melakukan perhitungan besarnya konsumsi energi pada bangunan gedung dan mengenali cara-cara untuk penghematannya. Penelitian tersebut meliputi audit energi awal dan audit energi rinci. Gedung-gedung yang diaudit berada di universitas Lampung. Dilakukan pula pencarian peluang penghematan energi pada gedung-gedung tersebut. Dari hasil penelitian itu, didapatkan bahwa IKE rata-rata adalah $34,31 \mathrm{kWh} / \mathrm{m}^{2} /$ tahun. Pada GSG IKE $26,89 \mathrm{kWh} / \mathrm{m}^{2} / \mathrm{tahun}$, dan pada Gedung A Fakultas Pertanian IKE rata-rata adalah $77,74 \mathrm{kWh} / \mathrm{m}^{2} /$ tahun. Sementara itu, Dewi dkk [3] melakukan penelitian audit energi yang bertujuan untuk mengetahui penggunaan energi di rumah sakit serta mencari peluang penghematan. Wijiastuti [4], melakukan penelitian di Universitas Gajah Mada (UGM), pada gedung daya pencahayaan maksimal namun daya suhu ruangan yang dapat meningkat. Hasil penelitian menunjukkan bahwa sistem tata udara memiliki beban daya listrik sebesar $76 \%$, sistem penunjang operasional sebesar $14 \%$ dan sistem tata cahaya memiliki beban terkecil sebesar $10 \%$. Perhitungan IKE gedung perpustakaan pusat UGM memberikan hasil $52,068 \mathrm{kWh} / \mathrm{m}^{2}$. Daya pencahayaan untuk perpustakaan adalah sebesar $2,93 \mathrm{~W} / \mathrm{m}^{2}$. Beberapa penelitian terkait audit energi telah banyak dilakukan $[5,6]$.

\section{METODE PENELITIAN}

\section{A. Waktu dan Tempat Penelitian}

Penelitian ini dilakukan mulai bulan Oktober sampai bulan Desember dengan mengambil data di PT Satwa Utama Raya 8 desa Baring, kota Pankep, Kec.Segeri, Kabupaten Pangkajene Kepulauan. 


\section{B. Pelaksanaan audit energi awal}

Mengambil data-data awal tentang penggunaan energi dalam industri seperti penggunaan energi listrik dan energi bahan bakar (data-data penggunaan energi yan diambil selama 24 bulan terhitung dari bulan januari 2014 sampai bulan Desember 2015). Mengambil data-data produksi dari PT Satwa Utama Raya sesuai dengan pengambilan data penggunaan energi. Membandingkan penggunaan energi dengan hasil produksi yang dihasilkan dalam waktu yang sama dengan membuat grafik perbandingan. Dengan cara ini, dapat dibuat suatu asumsi tentang boros atau tidaknya penggunaan energi.

\section{Pelaksanaan audit energi rinci}

Melaksanakan pengukuran secara langsung pada peralatan yang ada di PT Satwa Utama Raya yang mengkonsumsi energi. Melaksanakan wawancara kepada karyawan tentang penggunaan energi di dalam industri. Mengumpulkan data baik itu data dasar maupun data hasil pengukuran, kemudian melaksanakan analisi data. Membuat rekomendasi untuk pelaksanaan konservasi energi di dalam industri tersebut.

\section{Pengumpulan Data}

Setelah melaksanakan pengukuran pada suatu alat yang diteliti, penulis akan melaksanakan suatu pengumpulan data yang nantinya data tersebut sudah bisa dipercaya keakuratannya. Data-data yang diambil adalah data pemakaian energi yang di tahun sebelumnya, data pemakaian bahan bakar, data produksi, data biaya rekening listrik, data motor beserta daya yang terpakai pada motor, data pompa, serta data-data peralatan yang terpakai di industri. Dari data-data yang akan diambil untuk melakukan pengukuran listrik dengan menggunakan alat tang Ampere serta menggunakan alat ukur yang terbaca dipanel listrik.

\section{E. Metode Analisis Data dan Evaluasi}

Setelah melaksanakan pengumpulan data yang telah dianggap akurat, penulis selanjutnya akan melaksanakan suatu analisis data yang telah dikumpulkan, setelah itu maka segala bentuk permasalahan yang dihadapi pada industri tersebut akan diberikan jalan keluar dengan memberikan suatu rekomendasi tentang apa saja yang sebaiknya dilakukan guna pelaksanaan penghematan energi pada industri tersebut.

\section{HASIL DAN PEMBAHASAN}

\section{A. Energi Awal}

- Data produksi telur

Secara keseluruan produksi PT Satwa Utama Raya memproduksi telur ayam. Dimana telur tersebut yang ditetaskan kembali di perusahaan penetasan yang namanya Hatchery.

Tabel 1. Data produksi pada tahun 2014

\begin{tabular}{|c|c|c|}
\hline Bulan & Jumlah Produksi (Butir) & Berat (kg) \\
\hline Januari & 0 & 0 \\
\hline Februari & 0 & 0 \\
\hline Maret & 0 & 0 \\
\hline April & 0 & 0 \\
\hline Mei & 0 & 0 \\
\hline Juni & 126.926 & $7.615,56$ \\
\hline Juli & 2.165 .562 & $129.933,72$ \\
\hline Agustus & 6.370 .094 & $382.205,6$ \\
\hline September & 7.921 .228 & $475.273,7$ \\
\hline Oktober & 8.363 .727 & $501.823,6$ \\
\hline November & 9.561 .562 & $573.693,7$ \\
\hline Desember & 6.911 .672 & $414.700,3$ \\
\hline Jumlah Produksi & 41.420 .771 & $2.485 .246,18$ \\
\hline
\end{tabular}

Sumber : Data Sekunder 2014 
- Data pemakaian energi listrik

Berikut adalah data-data konsumsi energi serta alokasi di PT Satwa Utama Raya 8 selama 2 tahun periode 2014 dan 2015.

Tabel 2. Data konsumsi energi listrik pada tahun 2014

\begin{tabular}{|c|c|c|c|c|c|c|}
\hline Bulan & $\begin{array}{c}\text { Stand } \\
\text { Awal dan } \\
\text { Akhir }\end{array}$ & $\begin{array}{c}\text { Pemakai } \\
\text { an } \\
\text { LWBP } \\
\text { (kWh) }\end{array}$ & $\begin{array}{c}\text { Stand } \\
\text { Awal dan } \\
\text { Akhir }\end{array}$ & $\begin{array}{c}\text { Pemakaia } \\
\text { n WBP } \\
(\mathbf{k W h})\end{array}$ & $\begin{array}{c}\text { Pemakaian } \\
\text { Energi } \\
(\text { kWh) }\end{array}$ & $\begin{array}{c}\text { Biaya } \\
\text { Energi (Rp) }\end{array}$ \\
\hline \multirow{2}{*}{ Jan } & 51,45 & \multirow{2}{*}{$17.336,25$} & 4,74 & \multirow{2}{*}{1.035} & \multirow{2}{*}{$18.371,25$} & \multirow{2}{*}{17.826 .600} \\
\hline & 68,2 & & 5,74 & & & \\
\hline \multirow{2}{*}{ Feb } & 68,2 & \multirow{2}{*}{0} & 5,74 & \multirow{2}{*}{$5.454,45$} & \multirow{2}{*}{$5.454,45$} & \multirow{2}{*}{17.826 .600} \\
\hline & 68,2 & & 11,02 & & & \\
\hline \multirow{2}{*}{ Mar } & 68,2 & \multirow{2}{*}{$39.899,25$} & 11,02 & \multirow{2}{*}{$16.011,45$} & \multirow{2}{*}{$55.910,7$} & \multirow{2}{*}{39.671 .412} \\
\hline & 106,75 & & 26,49 & & & \\
\hline \multirow{2}{*}{ Apr } & 106,75 & \multirow{2}{*}{123.320} & 26,49 & \multirow{2}{*}{31.080} & \multirow{2}{*}{154.400} & \multirow{2}{*}{112.450 .540} \\
\hline & 230,07 & & 57,57 & & & \\
\hline \multirow{2}{*}{ Mei } & 230,07 & \multirow{2}{*}{185.930} & 57,57 & \multirow{2}{*}{48.090} & \multirow{2}{*}{234.020} & \multirow{2}{*}{170.760 .385} \\
\hline & 416 & & 105,66 & & & \\
\hline \multirow{2}{*}{ Jun } & 416 & \multirow{2}{*}{253.580} & 105,66 & \multirow{2}{*}{66.850} & \multirow{2}{*}{320.430} & \multirow{2}{*}{234.141 .946} \\
\hline & 669,58 & & 172,51 & & & \\
\hline \multirow{2}{*}{ Jul } & 669,58 & \multirow{2}{*}{260.200} & 172,51 & \multirow{2}{*}{68.380} & 328580 & 240040751 \\
\hline & 929,78 & & 240,89 & & 520.000 & 240.040 .131 \\
\hline Aoust & 929,78 & 204770 & 240,89 & 60460 & 265230 & 177731099 \\
\hline Agust & $1.134,55$ & 204.170 & 301,35 & 00.400 & 205.250 & 111.709890 \\
\hline & $1.134,55$ & 204260 & 301,35 & 55,430 & 259690 & 209622825 \\
\hline Sept & $1.338,81$ & 204.260 & 356,78 & 55.430 & 259.690 & $209,622,825$ \\
\hline & $1.338,81$ & 320920 & 356,78 & 81870 & 411790 & 377784414 \\
\hline Okt & $1.668,73$ & 329.920 & 438,65 & $81.8 / 0$ & 411.190 & $3 / 1.184 .414$ \\
\hline Nov & $1.668,73$ & 231930 & 438,65 & 63060 & 294990 & 335985284 \\
\hline Nov & $1.900,66$ & 231.930 & 501,71 & 63.060 & 294.990 & 335.985 .284 \\
\hline Des & $1.900,66$ & 244690 & 501,71 & 62670 & 307360 & 387630746 \\
\hline Des & $2.145,35$ & $24+.030$ & 564,38 & 0.070 & 501.500 & 301.050 .140 \\
\hline & nlah Pema & an Energi & n Biaya & & 1.950 .153 & 2.081.431.851 \\
\hline
\end{tabular}

Sumber: Data Sekunder 2014

- Data pemakaian bahan bakar solar

Kemudian untuk mengetahui beberapa jumlah pemakaian energi bahan bakar dikumpulkan mulai bulan januari 2014.

Tabel 3. Data pemakaian solar pada tahun 2014

\begin{tabular}{|l|c|}
\hline \multicolumn{1}{|c|}{ Bulan } & Liter \\
\hline Januari & 75 \\
\hline Februari & 75 \\
\hline Maret & 75 \\
\hline April & 100 \\
\hline Mei & 100 \\
\hline Juni & 500 \\
\hline Juli & 300 \\
\hline Agustus & 550 \\
\hline
\end{tabular}




\begin{tabular}{|l|c|}
\hline September & 250 \\
\hline Oktober & 210 \\
\hline November & 250 \\
\hline Desember & 1.202 \\
\hline Jumlah Pemakaian Solar & $\mathbf{3 . 6 9 7}$ \\
\hline
\end{tabular}

Sumber : Data Sekunder 2014

Tabel 4. Hasil analisa data dari intensitas energi pada audit energi awal tahun2014

\begin{tabular}{|c|c|c|c|c|}
\hline Bulan & Energi Listrik (kJ) & $\begin{array}{c}\text { Energi BBM } \\
(\mathbf{k J})\end{array}$ & $\begin{array}{c}\text { Produksi } \\
\text { Telur } \mathbf{( k g )}\end{array}$ & $\begin{array}{c}\text { Intensitas } \\
\text { Energi (kJ /kg) }\end{array}$ \\
\hline Januari & 66.136 .500 & 2.843 .925 & 0 & 0 \\
\hline Februari & 19.636 .020 & 2.843 .925 & 0 & 0 \\
\hline Maret & 201.278 .520 & 2.843 .925 & 0 & 0 \\
\hline April & $555,840,000$ & 3.791 .900 & 0 & 0 \\
\hline Mei & 842.472 .000 & 3.791 .900 & 0 & 0 \\
\hline Juni & 1.153 .548 .000 & 18.959 .500 & $7.615,56$ & 153.962 \\
\hline Juli & 1.182 .888 .000 & 11.375 .700 & $129.933,72$ & 9.191 \\
\hline Agustus & 954.828 .000 & 20.855 .450 & $382.205,6$ & 2.552 \\
\hline September & 934.884 .000 & 9.479 .750 & $475.273,7$ & 1.986 \\
\hline Oktober & 1.482 .444 .000 & 7.962 .990 & $501.823,6$ & 2.969 \\
\hline November & 1.061 .964 .000 & 9.479 .750 & $573.693,7$ & 1.867 \\
\hline Desember & 1.106 .496 .000 & 45.578 .638 & $414.700,3$ & 2.778 \\
\hline $\begin{array}{c}\text { IKE Rata-rata pada } \\
\text { tahun 2014 }\end{array}$ & 7.877 .052 .000 & 123.691 .778 & 2.485 .246 & 3.219 \\
\hline
\end{tabular}

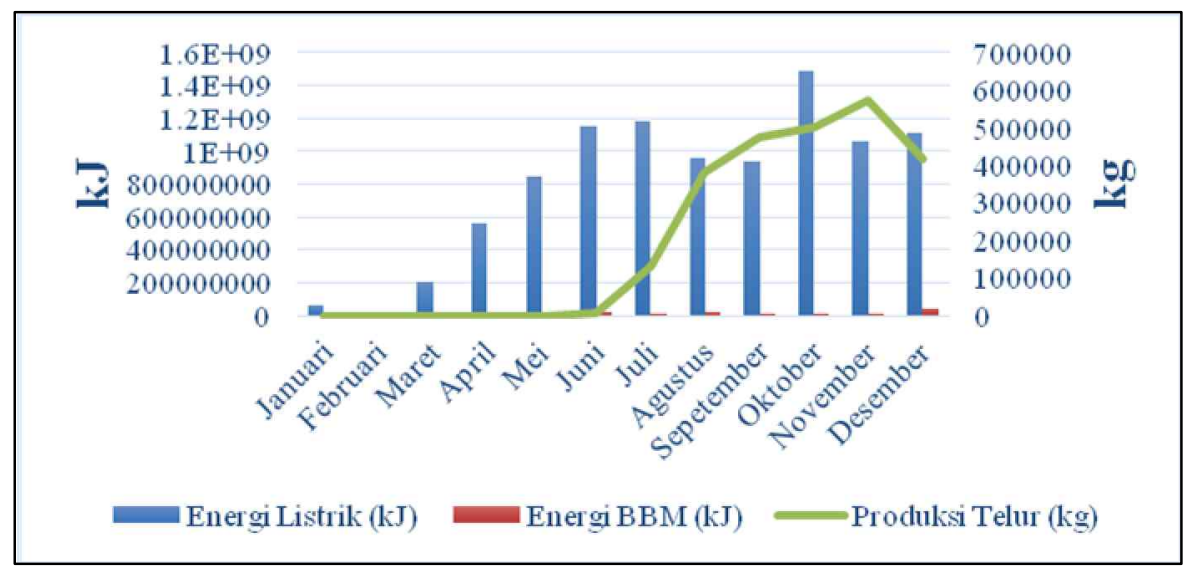

Gambar 1. Grafik konsumsi energi listrik (kJ), dan konsumsi energi bahan bakar solar (kJ) dengan produksi telur (kg) pada audit energi awal Tahun 2014 


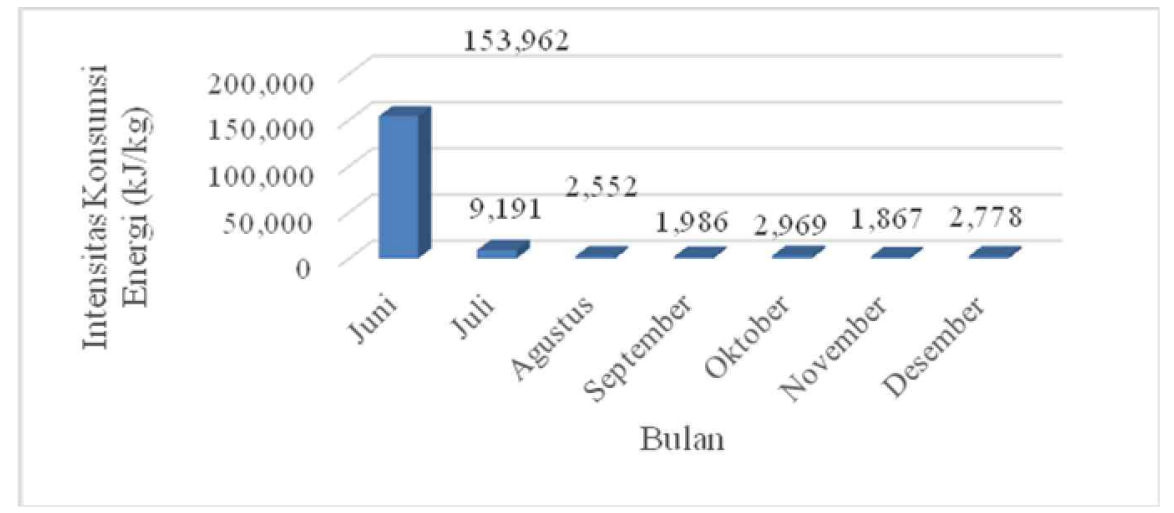

Gambar 2. Grafik intensitas konsumsi energi (kJ/kg) terhadap bulan pada audit energi awal Tahun 2014

\section{B. Audit Energi Rinci}

- Peralatan dalam sistem penerangan

Ada suatu kegiatan yang dilakukan untuk dapat menghemat penggunaan energi, untuk melihat seberapa besar konsumsi energi yang digunakan dalam sistem penerangan. Berdasarkan beban yang tersuplai, didapatkan di lapangan bahwa pada sistem penerangan dan peralatan listrik lainnya memerlukan energi sebesar 132.088,6 kWh. Cara mendapatkan jumlah energi tersebut yaitu dengan cara menjumlahkan semua jam operasional dari sistem penerangan dan menjumlahkan semua daya yang ada pada sistem penerangan. Hasil dari penjumlahan jam operasional dikalikan jumlah hasil daya pada lampu dan dikalikan 1 bulan (30 hari). Sehingga energi yang didapatkan sebesar 132.088,6 kWh.

\section{- Peralatan-peralatan pada sistem beban motor}

Dari pengamatan yang dilakukan pada sistem beban motor dapat dilihat beberapa kondisi yang dapat menurunkan efisien dan umur dari peralatan misalnya adanya beban tak seimbang yang masuk ke beberapa motor yang mana beban R, S, T untuk motor 3 fasa tidak seimbang hingga dapat menyebabkan adanya beban antar fasa kurang. Konsumsi enrgi yang terpakai pada peralatan hen house sebesar 184,24 kWh. Untuk data peralatan yang terpasang pada hen house.

Berdasarkan beban yang disuplai, penulis dapatkan di lapangan bahwa pada peralatan yang terpasang pada 25 Hen house memerlukan energi sebesar $4.531 \mathrm{kWh}$. Berdasarkan beban yang disuplai, penulis dapatkan di lapangan bahwa pada peralatan yang terpasang di sanitasi memerlukan energi sebesar 157,36 kWh. Berdasarkan beban yang akan disuplai, didapatkan di lapangan bahwa pada peralatan listrik lainnya memerlukan energi sebesar 446,3 kWh.

Berdasarkan data hasil pengukuran langsung pada peralatan listrik yang terpasang pada 25 Hen house, peralatan di area sanitasi, sistem penerangan dan peralatan listrik lainnya diperoleh konsumsi energi yang dihasilkan sebesar 137.241,3 kWh.

Tabel 5. Hasil analisa data dari intensitas energi pada audit energi rinci tahun 2014

\begin{tabular}{|c|c|c|c|c|}
\hline Bulan & $\begin{array}{c}\text { Energi Listrik } \\
(\mathbf{k J})\end{array}$ & Energi BBM (kJ) & $\begin{array}{c}\text { Produksi } \\
\text { Telur (kg) }\end{array}$ & $\begin{array}{c}\text { Intensitas } \\
\text { Konsumsi Energi } \\
\text { (IKE) (kJ /kg) }\end{array}$ \\
\hline Januari & 55.760 .400 & 2.843 .925 & 0 & 0 \\
\hline Februari & 8.424 .000 & 2.843 .925 & 0 & 0 \\
\hline Maret & 10.008 .000 & 2.843 .925 & 0 & 0 \\
\hline April & 45.000 .000 & 3.791 .900 & 0 & 0 \\
\hline Mei & 731.520 .000 & 3.791 .900 & 0 & 0 \\
\hline Juni & 1.062 .180 .000 & 18.959 .500 & $7.615,56$ & 141.964 \\
\hline Juli & 1.090 .782 .000 & 11.375 .700 & $129.933,72$ & 8.482 \\
\hline
\end{tabular}




\begin{tabular}{|c|c|c|c|c|}
\hline Agustus & 848.808 .000 & 20.855 .450 & $382.205,6$ & 2.275 \\
\hline September & 808.416 .000 & 9.479 .750 & $475.273,7$ & 1.720 \\
\hline Oktober & 138.816 .0000 & 7.962 .990 & $501.823,6$ & 2.782 \\
\hline November & 967.320 .000 & 9.479 .750 & $573.693,7$ & 1.702 \\
\hline Desember & 967.680 .000 & 45.578 .638 & $414.700,3$ & 2.443 \\
\hline Rata-rata & 706.744 .200 & 11.650 .612 & 2.485 .246 & 3.268 \\
\hline
\end{tabular}

Sumber : Data Primer 2015

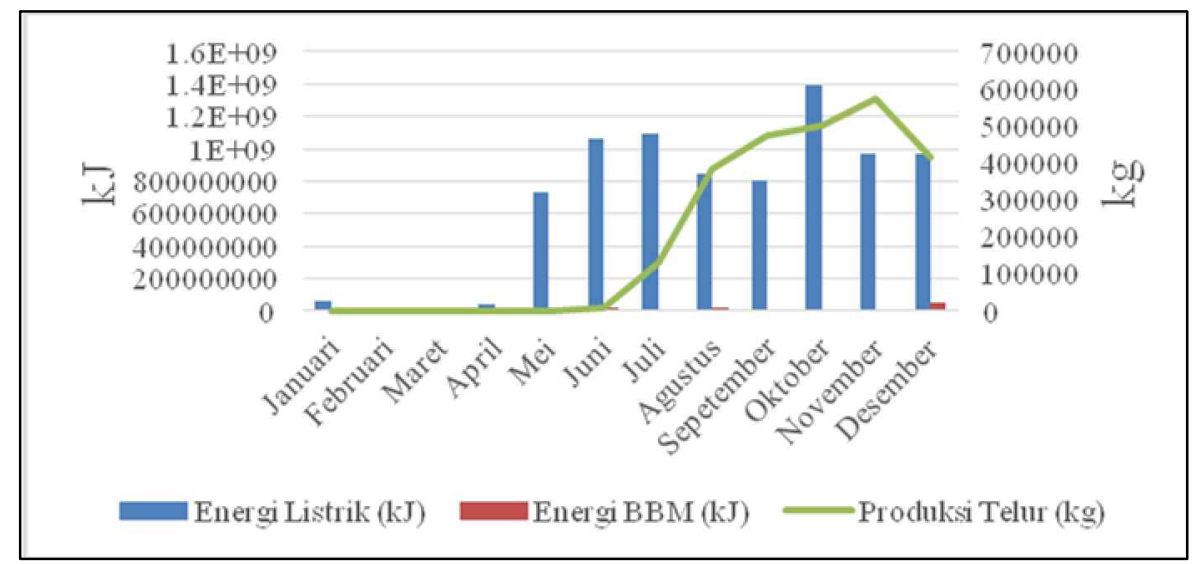

Gambar 4. Grafik Konsumsi Energi Listrik (kJ), Konsumsi Energi Bahan Bakar Solar (kJ) dengan Produksi Telur (kg) pada audit energi rinci Tahun 2014

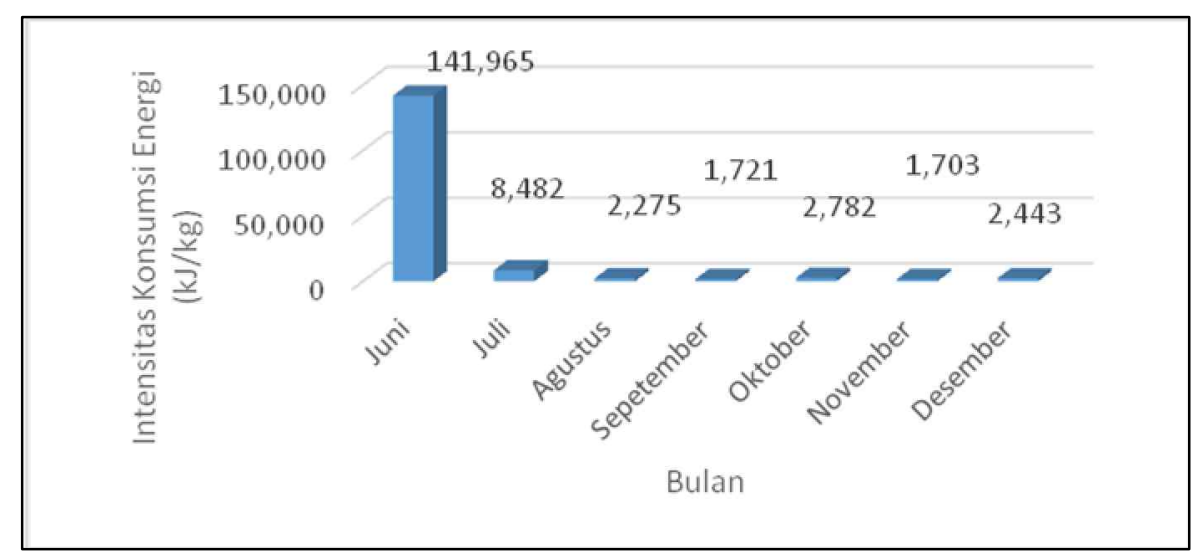

Gambar 5. Grafik Intensitas Konsumsi Energi Listrik (kJ) terhadap Bulan pada audit energi rinci Tahun 2014

Tabel 6. Hasil analisa data dari intensitas energi pada audit energi rinci tahun 2015

\begin{tabular}{|c|c|c|c|c|}
\hline Bulan & $\begin{array}{c}\text { Energi Listrik } \\
(\mathbf{k J})\end{array}$ & $\begin{array}{c}\text { Energi BBM } \\
(\mathbf{k J})\end{array}$ & Produksi (kg) & $\begin{array}{c}\text { Intensitas Konsumsi } \\
\text { Energi (IKE) (kJ } \\
\text { /kg) }\end{array}$ \\
\hline Januari & 1.004 .159 .736 & 30.714 .390 & $476.195,04$ & 2.173 \\
\hline Februari & 961.787 .736 & 36.060 .969 & $352.677,24$ & 2.829 \\
\hline Maret & 876.863 .736 & 379.190 & $319.051,56$ & 2.749 \\
\hline April & 974.492 .136 & 4.360 .685 & $275.167,08$ & 3.557 \\
\hline Mei & 880.679 .736 & 19.907 .475 & $216.172,2$ & 4.166 \\
\hline Juni & 669.467 .736 & 2.843 .925 & $68.359,44$ & 9.834 \\
\hline Juli & 269.255 .736 & 5.687 .850 & 0 & 0 \\
\hline
\end{tabular}




\begin{tabular}{|c|c|c|c|c|}
\hline Agustus & 71.219 .736 & 7.583 .800 & 0 & 0 \\
\hline September & 35.424 .000 & 3.791 .900 & 0 & 0 \\
\hline Oktober & 168.887 .736 & 5.687 .850 & 0 & 0 \\
\hline November & 313.103 .736 & 11.375 .700 & 0 & 287.165 \\
\hline Desember & 494.149 .500 & 13.271 .650 & 1.767 & 4.013 \\
\hline Rata-rata & 559.945 .458 & 11.805 .448 & $1.709389,56$ & \\
\hline
\end{tabular}

Sumber : Data Primer 2015

$$
\begin{array}{rr}
1.2 \mathrm{E}+09 \\
1 \mathrm{E}+09 \\
800000000 \\
600000000 \\
400000000 \\
200000000 \\
0
\end{array}
$$

Gambar 6. Grafik Konsumsi Energi (kJ), Konsumsi Energi Bahan Bakar Solar (kJ) dengan Produksi Telur (kg) pada audit energi rinci Tahun 2015

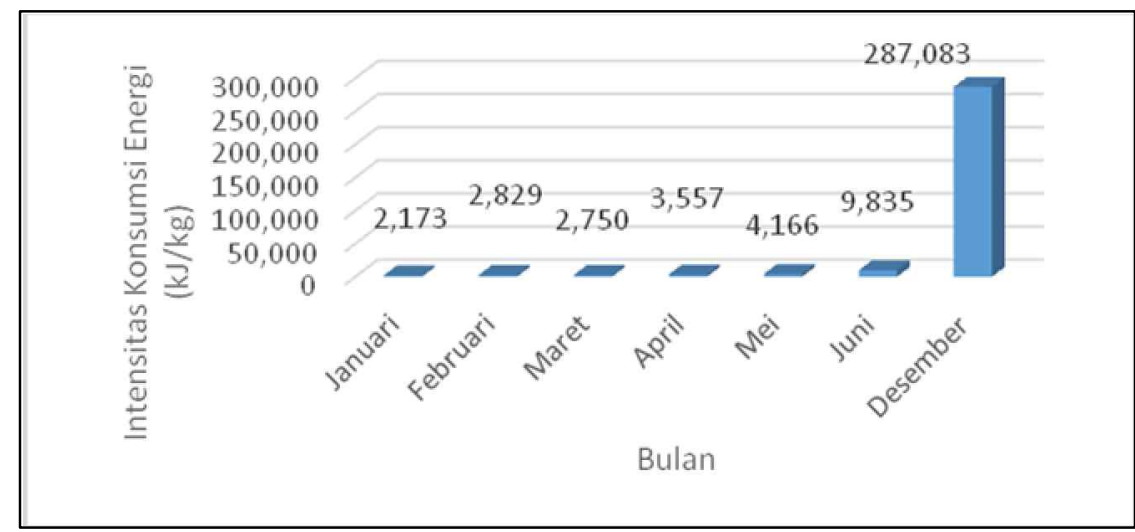

Gambar 7. Grafik Intensitas Konsumsi Energi (kJ) terhadap Bulan pada audit energi rinci Tahun 2015

\section{Analisis Situasi Penggunaan Energi dan Potensi Penghematan Energi}

Dalam menganalisis penggunaan energi pada PT Satwa Utama Raya dilakukan berdasarkan datadata yang dapat dikumpulkan baik dari hasil pengamatan maupun informasi dari pihak perusahaan serta asumsi-asumsi yang diambil.

\section{- Sistem AC (Air Conditioner)}

Bila ditinjau secara mendasar bahwa tujuan sistem tata udara (AC) adalah untuk menciptakan kenyamanan termal, bagi penghuni dalam suatu ruangan dengan cara mengendalikan secara serentak suhu, kelembapan udara, kecepatan aliran-aliran dan kebersihan udara. Dari pengukuran dan pengamatan terhadap sistem AC di dalam perusahaan, ada beberapa peluang yang cukup baik untuk diadakan penghematan energi, yaitu :

1. Penurunan thermostat suhu 
Pengukuran penggunaan energi AC sebesar 21,25 kW dengan jam operasionalnya 10 jam dan total pemakaian rata-rata selama sebulan adalah $6.375 \mathrm{kWh}$ per bulan. Diperkiran energi yang dapat dihemat ketika suhu thermostat di naikkan bisa mencapai 5\% yang berkisar 318,75 kWh.

2. Mereduksi infiltrasi udara

Infiltrasi udara dari luar ke dalam ruangan yang menggunakan sistem AC dapat memperbesar beban AC yang menyebabkan konsumsi energi bertambah. Hal ini perlu diperhatikan terutama pada kebocoran udara dapat memperbaiki "sealed" pada pintu atau objek lain yang menyebabkan kondisi optimum bagian $\mathrm{AC}$ sulit dicapai. Pintu-pintu yang memiliki ruangan $\mathrm{AC}$ harus dipasangkan pintu doorclose sehingga ketika masuk atau keluar rusngan pintu tersebut dapat tertutup sendiri.

\section{- Sistem Penerangan}

1. Pengurangan jam operasional lampu penginapan

Dengan melihat sistem penerangan, ada beberapa lampu yang dapat direkomendasi untuk potensi penghematan yaitu dari sistem penerangan penginapan. Berdasarkan jam kerja pada PT Satwa Utama Raya 8 yakni berkisar dari pukul 07:00-16:00 dan waktu istrahat pada pukul 11:30-13:30, biasanya lampu penginapan baru dapat dipadamkan pada saat waktu jam istrahat. Daya yang diperlukan pada sistem penerangan sebesar 1.370 Watt atau $1,37 \mathrm{~kW}$ yang jam operasional 18 jam sehari dan diperkirakan pemakaian energi selama 1 bulan sebesar 739,8 kWh. Jika pemakaiaan penerangan dilakukan secara efektif dengan mematikan lampu pada saat jam kerja yaitu 6 jam maka pemakaian energi 1,37 kW dikalikan 12 jam dan dikalikan selama 30 hari sebesar 493,2 kWh. Maka energi yang dapat di hemat adalah sebesar 246,6 kWh per bulan atau persentase sebesar 33.3\%. Hasil persentase di dapatkan berdasarkan 246,6 kWh / 739,8 kWh dikalikan 100\% sehingga didapatkan $33.3 \%$.

2. Membuat settingan program atau sensor

Lampu jalan memiliki 130 buah lampu dengan tipe lampu PL 20 Watt sehingga menjadi 2.600 Watt. Waktu beroperasinya sampai 13 jam yaitu dari 17:30 sampai 06:30. Setelah melihat kondisi penerangan yang berada di jalan raya dan di area perusahaan, lampu jalan dinyalakan dalm kondisi manual pada jam 17:30 sampai jam 06:30 yaitu selama 13 jam. Dalam kondisi tersebut pemakaian daya yang diperlukan pada sistem penerangan jalan sebesar $2,60 \mathrm{~kW}$ dan diperkirakan pemakaian energi selama satu bulan sebesar $1.014 \mathrm{kWh}$. Pengaturan menyalanya penerangan lampu jalan pada saat ini sangat terlalu cepat karena pada saat jam 17:30 kondisi masih cukup terang. Disarankan untuk memprogram ulang pengaturan menyalanya dan padamnya lampu jalan. Pada jam 18:30 lampu dinyalakan dan padamnya lampu jalan pada jam 05:30 yaitu jam operasionalnya 11 jam, atau memberikan sensor cahaya agar bisa menyala berdasarkan kondisi gelapnya cuaca. Sehingga energi yang di dapatkan diperkirakan 2,60 kWh dikalikan 11 jam dan dikalikan selama 30 hari, didapatkan konsumsi energinya adalah $858 \mathrm{kWh}$ perbulan. Jadi energi yang dapat dihemat sebesar $156 \mathrm{kWh}$ atau persentase sebesar 15,3\%. Hasil persentase didapatkan berdasarkan $156 \mathrm{kWh} / 1.014 \mathrm{kWh}$ dikalikan 100\% sehingga didapatkan $15,3 \%$.

Ketika rekomendasi itu dilakukan, secara keseluruhan dari penggunaan energi rata-rata sebesar 16,34 $\%$. Rata-rata dari biaya energi yang dibayar sebesar Rp. 370.000.000, sehingga dalam sebulan bisa menghemat energi sebesar Rp.60.458.000 didapatkan dari 0,1634 x Rp.370.000.00. Apabila melakukan penggunaan energi secara konsisten, maka dalam setahun bisa menghemat energi sebesar Rp.725.496.000.

\section{KESIMPULAN}

- Konsumsi energi listrik pada PT Satwa Utama Raya 8 dengan kurun waktu 2 tahun, yaitu nilai intensitas konsumsi energi listrik pada tahun 2014 sebesar $3.219 \mathrm{~kJ} / \mathrm{kg}$, sedangkan pada tahun 2015 intensitas konsumsi energinya sebesar $5.277 \mathrm{~kJ} / \mathrm{kg}$.

- Kenaikkan Intensitas konsumsi energi di tahun 2015 dikarenakan banyak masalah-masalah dan banyak tambahan program yang membutuhkan konsumsi energi yang banyak. 
- Selain itu, kebutuhan energi yang besar banyak terpakai tetapi hasil produksi yang ingin dicapai tidak sesuai dengan standar perusahan, bisa dikatakan di tahun 2015 merupakakan gagal produksi, sehingga di tahun 2015 intensitas konsumsi energinya lebih tinggi dibandingkan di tahun 2014.

- Mengurangi biaya konsumsi energi juga perlu kesadaran karyawan untuk melakukan penggunaan energi secara konsisten, serta mengadakan sosialisasi kepada seluruh karyawan agar perlunya melakukan penggunaan penghematan energi, dan membuat pampflet-pamflet atau stiker-stiker yang didalamnya mengandung kata-kata penggunaan penghematan energi agar bisa selalu mengingatkan dalam kesadaran penggunaan energi.

\section{DAFTAR PUSTAKA}

[1] A. W. Biantoro and D. S. Permana, "Analisis Audit Energi Untuk Pencapaian Efisiensi Energi Di Gedung Ab, Kabupaten Tangerang, Banten,” J. Tek. Mesin Mercu Buana, vol. 6, no. 2, pp. 85-93, 2017.

[2] J. Untoro, H. Gusnedi and N. Purwasih, "Perhitungan Besarnya Konsumsi Energi pada Bangunan Gedung dan Mengenali Cara-cara Untuk Penghematannya," Lampung, 2014.

[3] R. P. Dewi, Sarwono, R. Hantoro, "Audit Energi Konservasi Energi pada Rumah Sakit Angkatan Laut dr. Ramelan Surabaya," Fakultas Teknologi Industri, Institut Teknologi Sepuluh Nopember, 2013.

[4] F. Wijiastuti, “AUDIT ENERGI LISTRIK STUDI KASUS DI GEDUNG PERPUSTAKAAN PUSAT UGM SAYAP SELATAN (L1).” Universitas Gadjah Mada, 2014.

[5] E. Pratiwi, "Audit Energi Gedung Perkantoran (studi kasus di PT. PLN Distribusi Jawa Timur)." Universitas Gadjah Mada, 2013.

[6] H. Abdurarachim, D. A. Pasek, and T. A. Sulaiman, "Audit Energi, Modul 2, Energi Conservation Efficiency And Cost Saving Course.” Bandung: PT. Fiqry Jaya Mandiri, 2002. 